\title{
Use of Isoniazid Preventive Therapy on HIVIAIDS Patient in a Tertiary Health Facility South Eastern Nigeria
}

\author{
Nwokeukwu Huldah Ijeoma ${ }^{1}$, Okorie Onuka ${ }^{2}$, Emma-Ukaegbu Uloaku ${ }^{1}$, Ukegbu Andrew ${ }^{1}$, \\ Nwogu Kelechukwu', Ajuogu Eno', Osunkwo Damaris ${ }^{3}$, Asinobi Adanze ${ }^{4}$ \\ ${ }^{1}$ Department of Community Medicine, Federal Medical Centre, Umuahia, Abia State, Nigeria \\ ${ }^{2}$ State Ministry of Health, Abia State, Nigeria \\ ${ }^{3}$ Department of Internal Medicine, National Hospital Abuja, Federal Capital Territory, Abuja \\ ${ }^{4}$ Department of Paediatrics, University College Hospital, Ibadan, Oyo State Nigeria
}

Email address:

drhiln@yahoo.com (N. H. Ijeoma)

\section{To cite this article:}

Nwokeukwu Huldah Ijeoma, Okorie Onuka, Emma-Ukaegbu Uloaku, Ukegbu Andrew, Nwogu Kelechukwu, Ajuogu Eno, Osunkwo Damaris, Asinobi Adanze. Use of Isoniazid Preventive Therapy on HIV/AIDS Patient in a Tertiary Health Facility South Eastern Nigeria. Science Journal of Public Health. Vol. 3, No. 2, 2015, pp. 265-268. doi: 10.11648/j.sjph.20150302.26

\begin{abstract}
Introduction: The Human Immuno-deficiency virus / Acquired immune-deficiency syndrome (HIV/AIDs) is a very serious disease and pandemic. There have been series of interventions to combat the disease and these include, Prevention of mother to child transmission, HIV counseling and testing, treatment of HIV/AIDs with antiretroviral drugs and the three I's which include Intensive case search, Infection control and Isoniazid preventive therapy (IPT). There appears to be paucity of information on the IPT in our environment and it is therefore necessary to find out how the IPT has been implemented in this part of the world. Objective: To determine the number of Cases of HIV placed on IPT. Methodology: This is a cross sectional study in which the HIV patients who were placed on the IPT were identified and followed up. The situational analysis was carried out to identify those already placed on IPT. The next stage was training of the doctors on IPT and informing them on the importance of IPT in the management of HIV patients. Data tools were provided. A focal person was selected to fill these data tools to be able to get accurate number of HIV patients on IPT. Data was analyzed with Microsoft Excel and Epi. Info. Results: The total number of new cases of HIV seen from July to September 2013 was 218, of which (30\% N=65) was started on IPT. Of the 65 that started the IPT only $(63 \%, \mathrm{~N}=41)$ continued the second month. The number of suspected TB were $(2.3 \%$ $\mathrm{N}=5)$. The number of cases of TB- Co infection $(0.4 \% \mathrm{~N}=1)$. Conclusion: The IPT is being utilized in this health facility for prevention of TB in HIV/AIDs although at a low rate, however the creation of more awareness among Doctors and Patients and proper documentation, will further improve the uptake of IPT.
\end{abstract}

Keywords: HIV, AIDs, Isoniazid Preventive Therapy

\section{Introduction}

Human Immunodeficiency Virus infection is the strongest risk factor for developing tuberculosis (TB) disease in those with latent or new Mycobacterium tuberculosis infection. The risk of developing TB is between 20 and 37 times greater in people living with HIV than among those who do not have HIV infection. TB is responsible for more than a quarter of deaths in people living with HIV., ${ }^{1,2,4}$

Isoniazid Preventive therapy (IPT) is the use of Isoniazid in HIV Positive individuals with latent TB infection and under five contacts of PTB index cases in order to prevent the development of active TB disease. Available evidence shows that TB is the commonest opportunistic infection and the leading cause of death among People living with HIV/AIDS (PLWHA) and also that IPT is effective in preventing it'. The slogan 'IPT works, IPT is safe, IPT works by itself or with ART' is very popular ${ }^{2}$.

Research evidence exists that IPT markedly reduces the incidence of TB among people living with HIV and even among those receiving $\mathrm{ART}^{7}$.WHO and UNAID in a 1998 statement issued on the effectiveness of IPT recommended its use as part of essential care package for people living with HIV. It recommends IPT for all people living with HIV in 
areas with a prevalence of latent TB infection $>30 \%$ and for all people with documented latent TB infection or exposure to an infectious TB case, regardless of where they live. A reinforcing statement was released by the TB/HIV working group of the Stop TB Partnership in October $2007^{8,9}$.

Although TB represents a potential threat to the achievable benefits of HIV scale up care and treatment, IPT represents strong potential for reduction of mortality and morbidity in people living with $\mathrm{HIV}^{10}$. Therefore major effort should be made to identify, prevent and treat TB among people living with HIV in order not to lose on the progress made in care and treatment ${ }^{10}$. Preventive Treatment targets Infants of mothers with either Smear Negative or Positive PTB, Children under 5 years of age as TB contacts, HIV-infected individuals, Health care workers who are HIV positive and HIV positive prison inmates. IPT is not the treatment for active TB. It is therefore necessary to exclude active TB ${ }^{5,11}$

However, countries have been slow to adopt these recommendations and many limitations seem to be delaying effective nationwide implementation. In 2007, only 30000 $(0.1 \%)$ people living with HIV worldwide had started IPT ${ }^{12}$.

The reduction of TB incidence, prevalence and death 2015 could be achieved in most of the world but the challenge will be greatest in Africa and Europe ${ }^{12}$

It has been hypothesized that the reductive effect of IPT on the risk of developing $\mathrm{TB}$ is lifelong and has been documented in a study that the protection effect of Isoniazid prophylaxis is up to 19 years and shown to be related to the amount INH taken ${ }^{13}$

\section{Objective}

To determine the number of Cases of HIV placed on IPT

\section{Methodology}

This is a cross sectional study in which the HIV patients who were placed on the IPT were identified.

The situational analysis was carried out to identify those already placed on IPT. This was done in the first part of the study and reported above. Data was collected from records and analyzed with Excel.

The next stage was training of the doctors on IPT and informing them on the importance of IPT in the management of HIV patients. Data tools were provided. A focal person was selected to fill these data tools to be able to get accurate number of HIV patients on IPT and those that completed

Isoniazid was given $300 \mathrm{mg}$ daily for six months.

\section{Results}

The total number of new cases of HIV seen from July to September was 218 out of which $(30 \% \mathrm{~N}=65)$ was started on IPT. Out of the 65 that started the IPT only $(63 \%, \mathrm{~N}=41)$ continued the second month. The number of suspected TB were $(2.3 \% \mathrm{~N}=5)$. The number of cases of TB- Co infection $(0.4 \% \mathrm{~N}=1)$

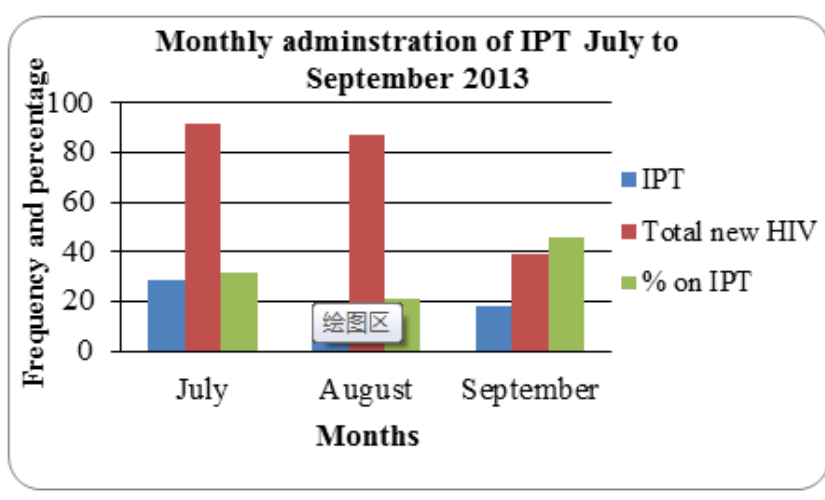

Figure 1. Monthly Administration of IPT

The percentage of cases put on IPT was more in September $46 \% \mathrm{~N}=18$ ) Although more cases of HIV/AIDs registered in August 2013

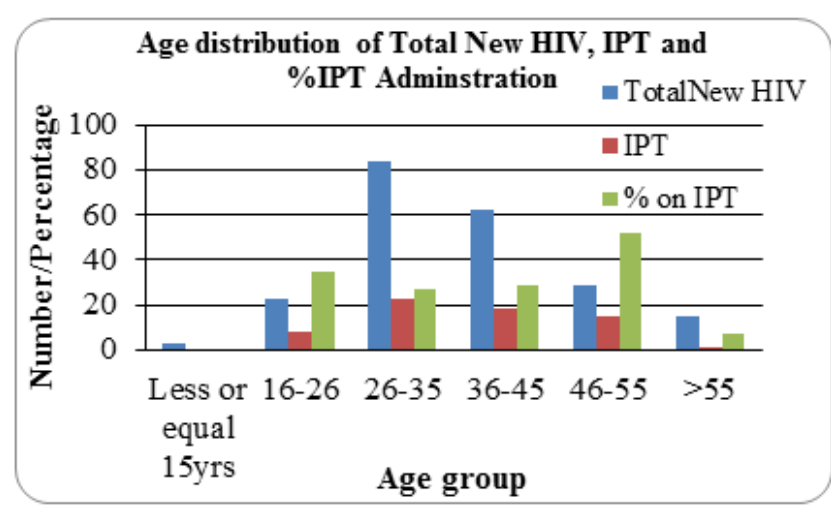

Figure 2. Age Distribution of IPT Admistration

Most of the cases of HIV/AIDs were within the age of 2635 years $(39 \% \mathrm{~N}=84)$ while the percentage put on IPT was more within the age group of $46-55$ years $(52 \% \mathrm{~N}=15)$.

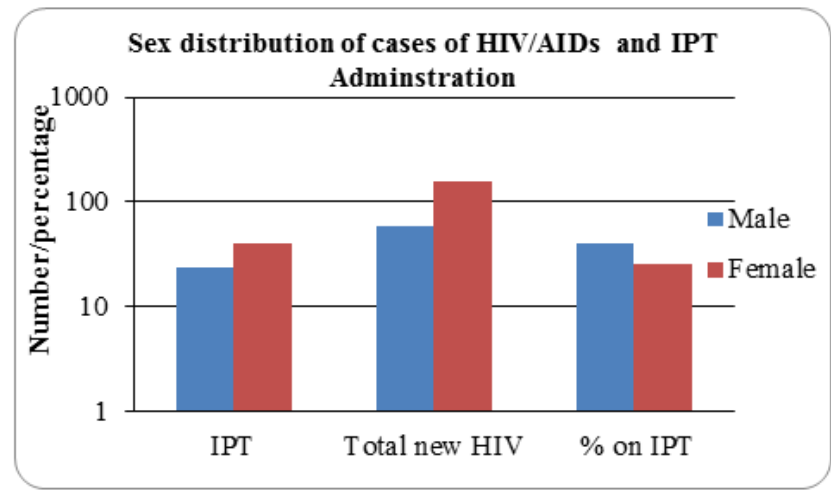

Figure 3. Sex distribution of Cases of HIV/AIDs and IPT Adminstration

Most of the cases of HIV/AIDs were females ( $73 \% \mathrm{~N}=159)$ while percentage on IPT were males $(41 \% \mathrm{~N}=24)$

The weight group $<30 \mathrm{~kg}$ to $60-69 \mathrm{~kg}$ cases were more than those on IPT while in group $70-79 \mathrm{~kg}$ were equal that of $>79 \mathrm{~kg}$ were more of IPT than cases. 


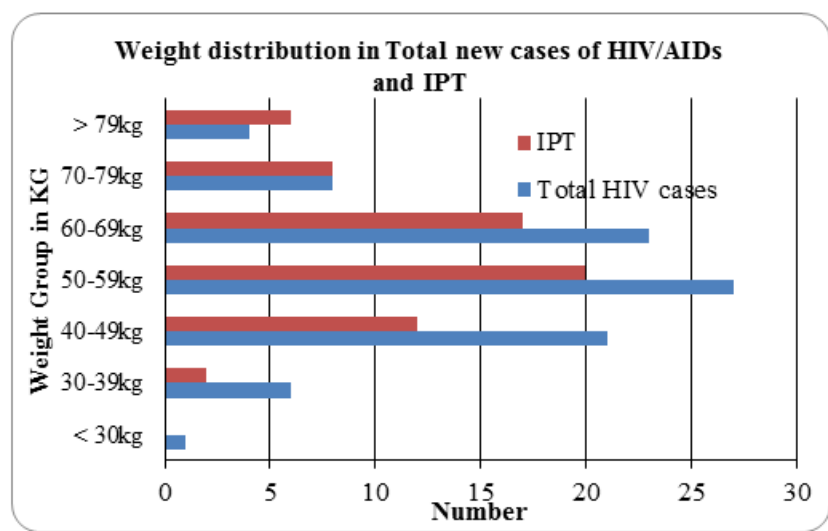

Figure 4. Distribution of Weight in cases of HIV/AIDs and on IPT

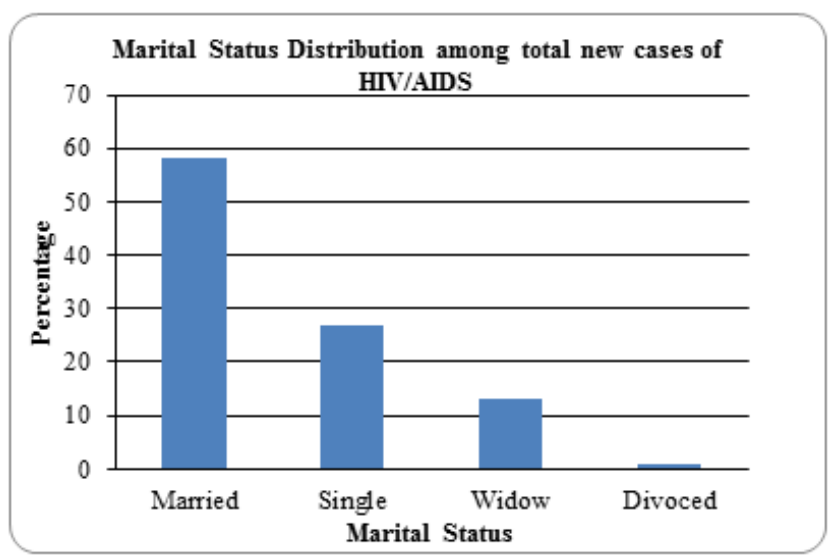

Figure 5. Marital Status distribution among HIV/AIDs

The HIV/AIDs patients were mainly married, followed by single, then widows and finally divorced

\section{Discussion}

There has been improvement in the number of cases that has been put on IPT considering the fact that for one year July 2012 to June 2013, it was 113 but within July to September 2013 a period of 3 months the number rose to 218 . The percentage uptake improved in September, although the uptake is very low generally. This could be due to the fact that Doctors still need to be reminded to screen the patients and put them on IPT. Hopefully with this achievement more patients will be put on IPT, as more awareness is being created among the doctors. This outcome is better than what was reported globally in 2007 where only $30000(0.1 \%)$ people living with HIV worldwide had started IPT ${ }^{14}$

The patients lost to follow up in this study is similar to what was seen in Uganda ${ }^{15}$ however that of Uganda is higher. It could also be that patients may not want to take the drug for a long time and some suggestion has been made to use Multi-drug or Rifampcin for shorter period ${ }^{16-18}$

The age group 26 to 35 years had the highest number of HIV but less in the percentage coverage of IPT. This could be due to the fact that, being an active group may look healthy and not see the need of taking additional drug. Further study could be conducted to identify the reason.
The sex distribution showed that females although more, the uptake of IPT was more with the males.

In this study there was increase in weight with those with IPT, this could be a sign of improvement due to the uptake of the IPT

Most of the patients were married, it also necessary to find out if the spouse is also infected, those on treatment and getting preventive measures.

\section{Conclusion and Recommendation}

The IPT is being utilized in this health facility in prevention of TB in HIV/AIDs although at a low rate, but with creation of more awareness among Doctors and Patients and proper documentation, there will be further improvement of IPT uptake. More work should be done on IPT to get the attrition rate and what could be done to reduce it and its effect in the reduction of TB co-infection in PLWHA.

\section{Acknowledgement}

CDC, PEFAR, E and F Management Consult LTD, Workers in Anti retroviral Centre.

\section{References}

[1] WHO. Guidelines for intensified tuberculosis case-finding and isoniazid preventive therapy for people living with HIV in resource-constrained settings. Department of HIV/AIDS. Stop TB Department World Health Organization, Geneva, Switzerland

[2] Isoniazid preventive therapy (IPT) for people living with HIV. Consensus statement of the Core Group of the TB/HIV Working Group of the Stop TB Partnership

[3] Mark FC. INH Preventive Therapy (IPT) In HIV-Infected South African Children .Southern African Journal of HIV Medicine, Vol 12, No 2 (2011)

[4] World Health Organisation. Policy for Collaborative TB/HIV Activities

[5] Federal Ministry of Health .Department of Public Health. Guidelines ForClinical Management of TB/HIV related conditions In Nigeria $2^{\text {nd }}$ edition,

[6] Golub JE. et al The impact of antiretroviral therapy and isoniazid preventive therapy on tuberculosis incidence in HIVinfected patients in Rio de Janeiro, Brazil. AIDS 2007; 21: 1441-8 doi: 10.1097/QAD.0b013e328216f441 pmid: 17589190

[7] WHO. Policy statement on preventive therapy against tuberculosis in people living with HIV. Geneva: World Health Organization; 1998 (WHO/TB/98.255).

[8] Consensus statement of the core group of TB/HIV Working Group of STOP TB partnership. Geneva:StopTBpartnership. Availablfrom:http://www.stoptb.org/wg/tb_hiv/assets/docume nts/IPT\%20Consensus\%20Statement $\% 20$ TB $\% 20 H I V \% 20$ Cor e\%20Group.pdf 
[9] Anand $\mathrm{AD}$ et al. Implementation of co-trimoxazole prophylaxis and isoniazid preventive therapy for people living with HIV. Bulletin of the World Health Organization 2010; 88:253-259. doi: 10.2471/BLT.09.066522

[10] Standards for Public Health; International Standards for Tuberculosis care: $2^{\text {nd }}$ edition 2009

[11] Dye C, Watt CJ, Bleed DM, Hosseini SM, Raviglione MC. Evolution of tuberculosis control and prospects for reducing tuberculosis incidence, prevalence, and deaths globally. Stop TB Department, World Health Organization, Geneva, Switzerland.dyec@who.int

[12] Comstock GW, Baum C, Snider DE Jr. Isoniazid prophylaxis among Alaskan Eskimos: a final report of the bethel isoniazid studies. US National Library of Medicine National Institutes of Health; PubMed

[13] Dye C, Watt CJ, Bleed DM, Hosseini SM, Raviglione MC. Evolution of tuberculosis control and prospects for reducing tuberculosis incidence, prevalence, and deaths globally. Stop TB Department, World Health Organization, Geneva, Switzerland.dyec@who.int
[14] Namuwengea PM, J.K. Mukonzo JK, Kiwanuka N, Wanyenze $\mathrm{R}$ Byaruhanga $\mathrm{R}$, Bissell $\mathrm{K}$, et al. Loss to follow up from isoniazid preventive therapy among adults attending HIV voluntary counseling and testing sites in Uganda. Transactions of the Royal Society of Tropical Medicine and Hygiene journal home page: http/ /www.elsevier.com/locate/trstmh

[15] Marais BJ, Susan VZ, Schaaf HS, Aardt MV, Gie RP, and Beyers N. Adherence to isoniazid preventive chemotherapy: a prospective community based study.C2006 BMJ Publishing Group \& Royal College of Paediatrics and Child Health Published online 2006 May 31. doi: 10.1136/adc.2006.097220

[16] WHO. Efficacy of various durations of isoniazid preventive therapy for tuberculosis: five years of follow-up in the IUAT trial. Bulletin of the World Health Organisation

[17] Kathleen RP, Frangiscos S, Reuben MD, Wendy AC, Meg CD, Lynn F. et al. Improved Adherence and Less Toxicity With Rifampin vs Isoniazid for Treatment of Latent Tuberculosis.A Retrospective Study. Arch Intern Med. 2006; 166:1863-1870 